\title{
Validation of high-precision effects of a movable riverbed simulation using unmanned aerial vehicles and structure from motion
}

\author{
Masatoshi Denda ${ }^{1, *}$ \\ ${ }^{1}$ Pubilic Works Research Institute Water environment department River Restoration team, 1-6 \\ Minamihara Tsukuba city Ibaraki Pref., Japan
}

\begin{abstract}
For advanced and strategic management of gravel riverbed restoration and stopping of woodland overgrowth, movable riverbed simulations and vegetation dynamic models that can describe a 'detailed riverbed materials' transport' influencing the vegetation dynamics and estimate the creation area of a gravel riverbed are required. As first steps we verified the hypothesis whether high-accuracy observation data using UAV and SfM improve the accuracy of water flow condition and movable riverbed simulation that can describe the riverbed materials' transport in detail. In the results, High-precision river morphology using UAVs offers the ability to improve the movable riverbed simulation. And these progresses indicated possibilities of UAV and SfM to develop vegetation dynamics model considering the riverbed materials' transport.
\end{abstract}

\section{Introduction}

The decrease in natural flood disturbances enhances the disappearance of typical river environmental landscapes, such as the conditions of a gravel riverbed, and promotes the succession to a woodland overgrowth [1]. In Japanese river ecosystems, not only hydrodynamic forces but also sediment transports disturb river morphology, riverbed conditions and vegetation conditions. These natural flood disturbances re-create the natural gravel riverbed conditions and inhibit its succession to a woodland. These natural flood disturbances are an important function to maintain the river ecosystem's health and discharge capacity. Japanese river researchers and river engineers have recognised that the transport of riverbed material recreates the gravel riverbed, and hydrodynamic forces, including riverbed materials' transport, flush and share the riverbed and vegetation via many river-improvement and river-restoration projects. Many river researchers and river engineers presently aim to conserve and restore natural flood disturbance and riverbed materials' transport to manage Japanese rivers.

For advanced and strategic management of gravel riverbed restoration and stopping of woodland overgrowth, movable riverbed simulations and vegetation dynamic models [2]. that can describe a 'detailed riverbed materials' transport' and estimate the creation area of

\footnotetext{
* Corresponding author : $\underline{\operatorname{denda}(\text { pwri.go.jp }}$
} 
a gravel riverbed are required. If we accurately characterise the 'detailed riverbed materials' transport', we can estimate the effects of the gravel bed restoration project and vegetation succession both quantitatively and in beforehand.

To describe riverbed materials' transport in detail, two types of approaches exist. The first involves an improvement of the sediment transport rate equation[3]. Studies based on this approach have been conducted by many Japanese researchers. The second approach involves the improvement via simulation conditions using high-precision observation data in increments. Although the second type is common in numerical weather simulations as data assimilation methods, it has not been applied to current river engineering studies.

At present, developments in spatial data observation and simulation such as unmanned aerial vehicles (UAV) and structure from motion (SfM) techniques are progressing rapidly [4]. If we apply these new techniques to setting the initial conditions of the movable riverbed simulation and increment new observation data to the next phase simulation condition, we will be able to reconstruct and estimate the 'detailed riverbed materials' transport. However, few studies have been conducted for this verification.

Based on this background, we verified the hypothesis whether high-accuracy observation data using UAV and SfM improve the accuracy of water flow condition and movable riverbed simulation that can describe the riverbed materials' transport in detail.

\section{Material and method}

\subsection{Study site}

The Chikuma River is the upper part of the Shinano River that is the longest river in the central part of the Nagano Prefecture, Japan; the river's basin area is about $11900 \mathrm{~km}^{2}$ and its total length is $367 \mathrm{~km}$. The Shinano River is a big river managed by the Ministry of Land Infrastructure, Transport and Tourism(Fig.1).

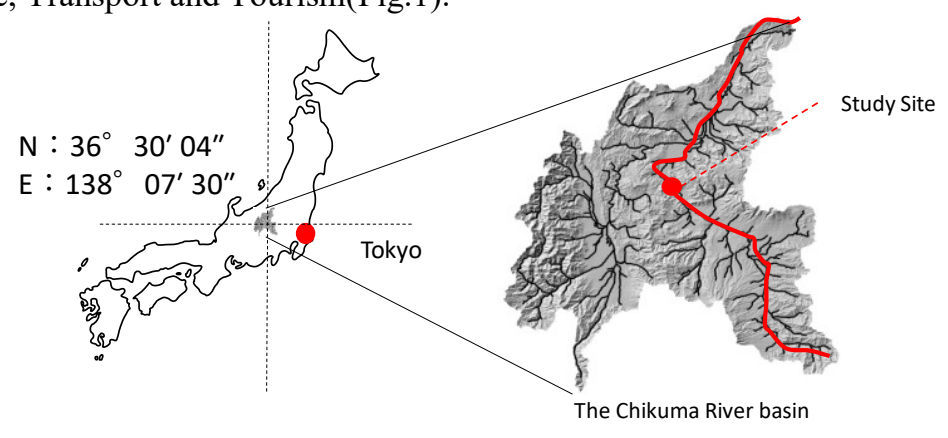

Fig.1 The Chikuma River

The study site, the Kamuriki district, is located at the central part of the Chikuma River, near Ueda city. At the study site, the channel width is $\approx 150 \mathrm{~m}$, and the river channel comprises gravel, sand bars and vegetation such as grass and woodland. Many endangered species depend on these gravel, sand bars and vegetated areas and inhabit the Chikuma River.

The decrease in the natural flood disturbance is caused by an increase in the elevation difference between the river channel and river terrace, owing to the gravel pit that has emerged because of the construction of social infrastructures (roads, bridges, buildings and so on) for economic growth (from the 1950s to 1970s).

In the upstream areas of the Chikuma River that include the Kamuriki district, riparian vegetation overgrowth, called woodland overgrowth, has become a major environmental 
management issue. Woodland overgrowth is caused by the decrease in natural flood disturbance stopping recreation of gravel bed condition and vegetation succession. In terms of the environment, the woodland overgrowth has degraded the gravel bed condition and the living conditions of the inhabitants that prefer this gravel bed.

\subsection{River-restoration project in study site}

To restore the gravel bed and sand bars and stop the woodland overgrowth, the Chikuma River management office, which is a part of the Ministry of Land Infrastructure, Transport and Tourism, Hokuriku Regional Development Bureau, has conducted a river-restoration project form FY2014 to FY2016. A characteristic of this restoration project was the combination of excavation and utilization of the old river channel. In order to reduce the cost of the excavation for decreasing the elevation difference between the river channel and river terrace works, the old river channel was used as a guide channel to introduce the flooding main flow into the river terrace and use this flooding to flush out the sediments and vegetation.

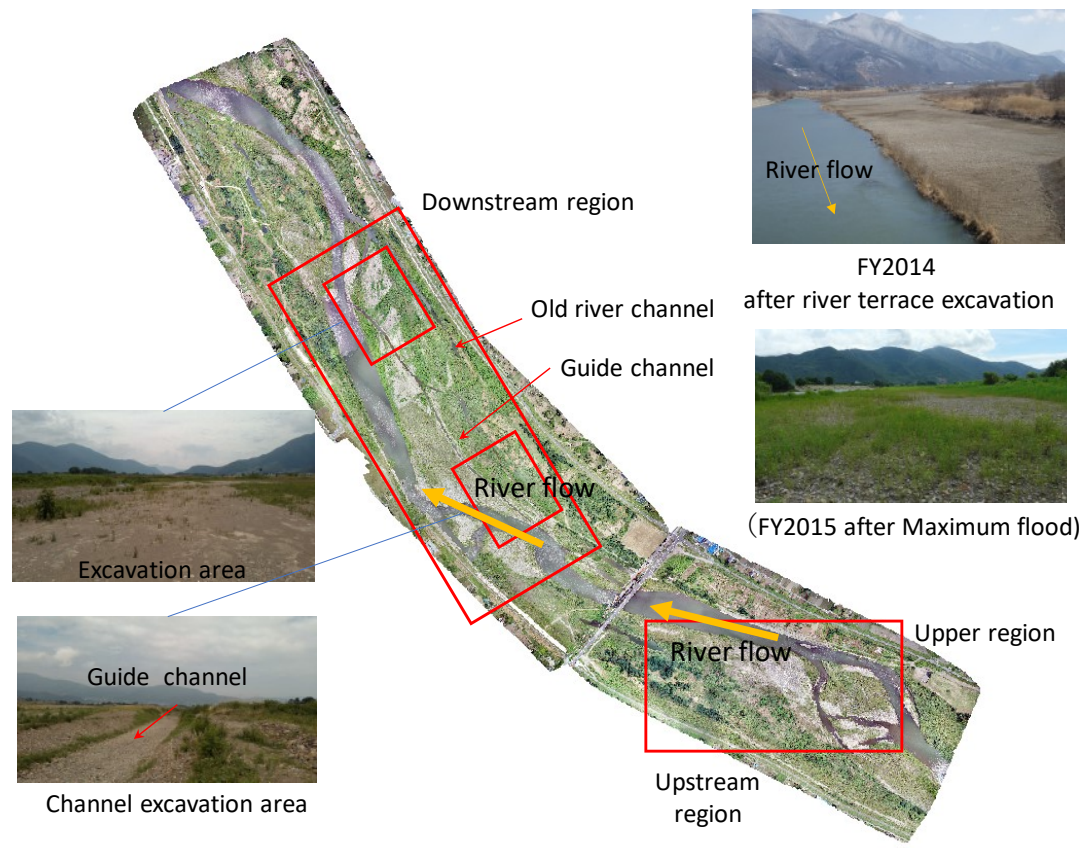

Fig. 2 The Kamuriki District

This project has been successful in creating and maintaining gravel bed conditions and has stopped vegetation succession over the last few years. By assessing the restoration results, we recognized that sediment transport has been instrumental in restoring the gravel bed conditions and flushing (curbing) the initial vegetation growth. This recognition indicated that reconstruction and detailed estimation of the riverbed material transport were key phenomena for the quantitative design of the restoration project on the gravel bed's condition. If the movable riverbed simulation can be used to accurately simulate the riverbed material's transport in detail, it will help the river manager strategically plan the management of the gravel bed condition and the woodland overgrowth. 


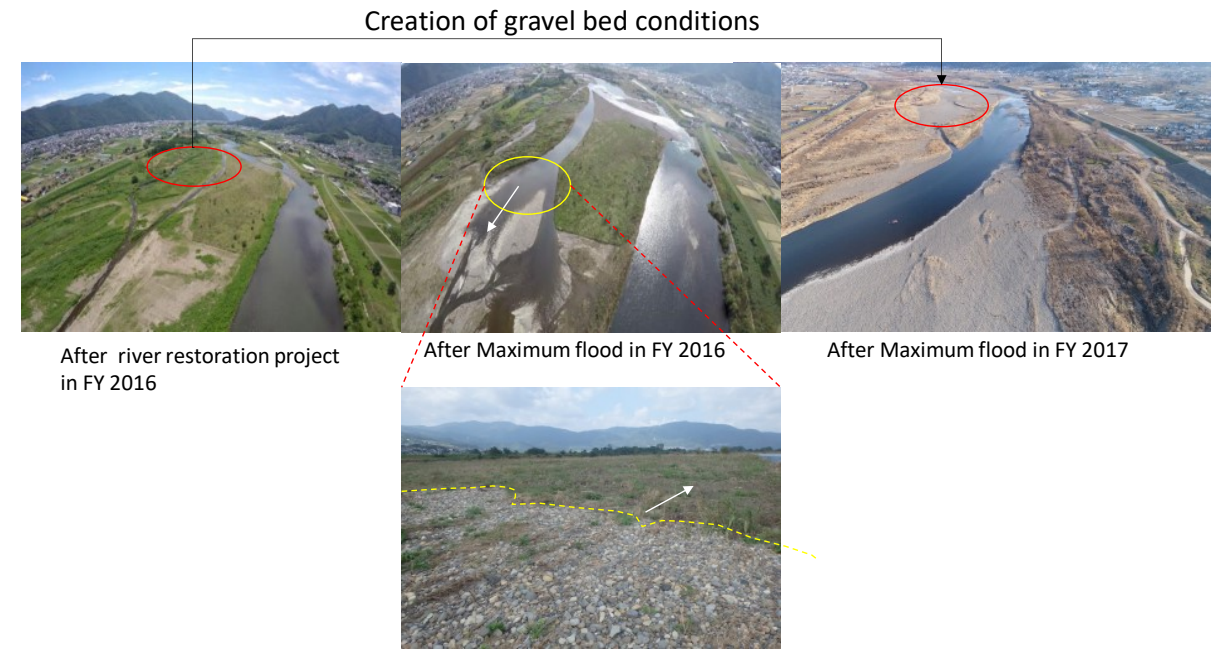

Fig. 3 Relationships between detailed riverbed materials' transport[5] and creation of the gravel riverbed condition.

\subsection{Proposed method in our research and the first trial of the proposed method in this research}

At present, observation and analysis techniques, such as UAV and SfM, are rapidly developing. It is hypothesized that UAV and SfM have the potential to improve the movable riverbed simulation. A UAV can be used to easily and economically observe river morphology and vegetation growth conditions, when compared with traditional remotesensing methods requiring the use of airplanes. The conveniences enhance high-frequency observations of river morphology and vegetation growth conditions.

High-frequency observations present a new spread for movable riverbed simulation and the vegetation dynamics model. A keyword associated with the new spread is "data assimilation". Data assimilation means determining the best possible simulation state using observations and short-range forecasts. In a numerical weather simulation that has an intrinsic uncertainty, data assimilation is commonly applied and provides good prediction results.

River ecosystems are similarly influenced by uncertainties, such as flood occurrence. These uncertainties help in the prediction of river ecosystems comprising river morphology and vegetation dynamics.

This research proposes a new observation and simulation scheme, as shown in Fig. 4 This scheme proposes a high precision for the initial simulation condition and a revision of rules concerning vegetation dynamics, such as flushing out and vegetation succession corresponding to observation data. For a traditional initial condition settlement, crosssectional survey data are interpolated. Although these interpolation methods can not represent a detailed river morphology, a UAV and SfM can be used to reconstruct details of the river morphology and vegetation growth condition. Also, details of vegetation conditions acquired via UAV and SfM can provide information about the flushing out of grasses and wood by flood and a vegetation succession after floods. Applying such information to vegetation dynamics models enhances the improvement of vegetation dynamics rules associated with the vegetation dynamics models. Through these improvements, the vegetation dynamics model can be used to more accurately predict complex river morphology changes and vegetation dynamics. 
In this study, as the first step, we verify the accuracy of river morphology via a UAV and $\mathrm{SfM}$. Then, the difference between the low-accuracy interpolated river morphology data and the high-accuracy river morphology data determined the result of the detailed riverbed materials' transport.

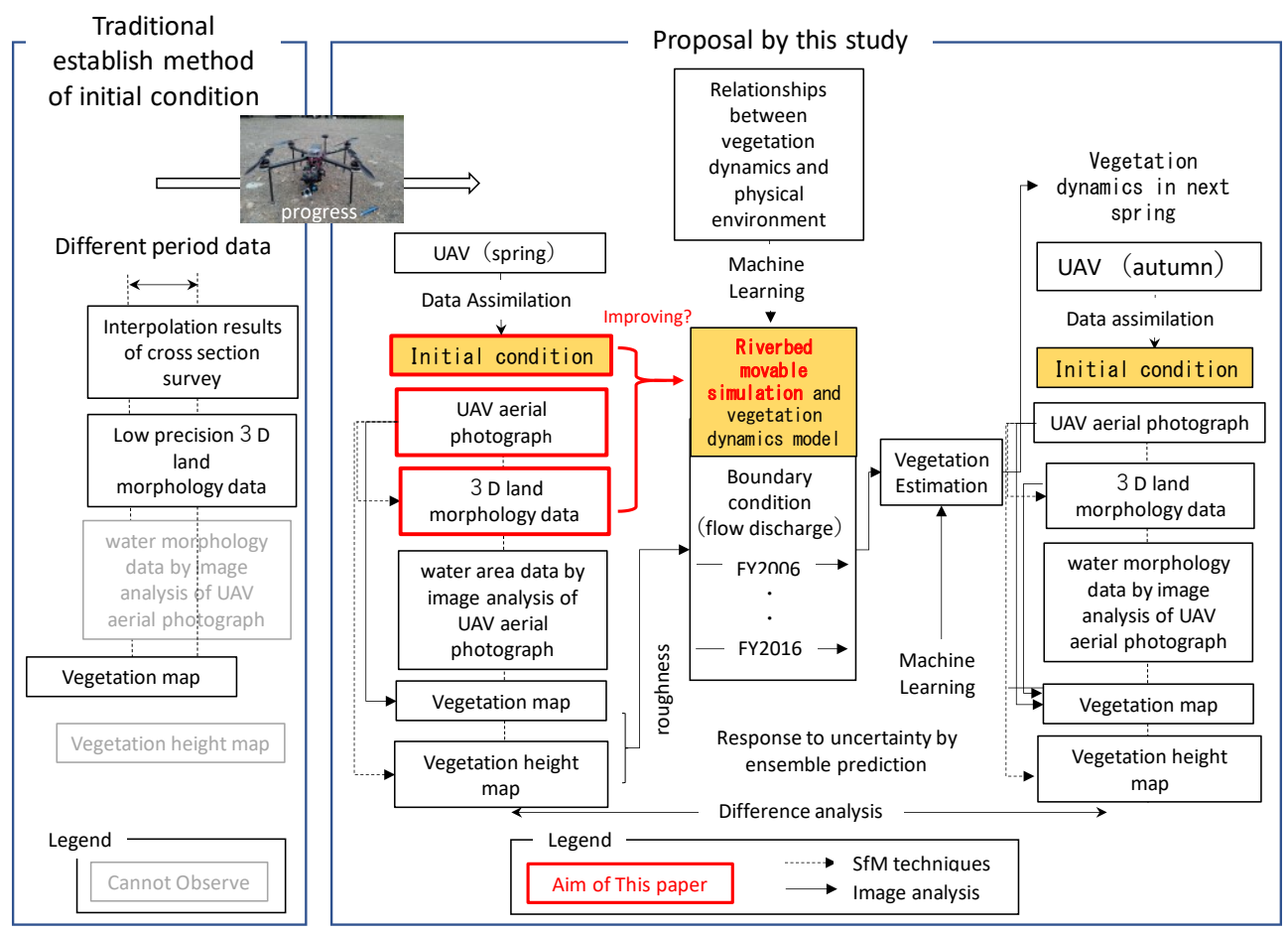

Fig. 4 The schematic of the proposed method and a comparison with traditional river morphology estimation methods.

\subsection{Field survey}

We conducted two field surveys on 5 July and 25 October 2016, using UAVs. We set 25 grand configuration points (GCP) in the study site using UAVs (EnRout Co. Ltd; Zion QC730) and took low-altitude aerial photographs (altitude from grand surface was $100 \mathrm{~m}$, resolution was $\approx 2.5 \mathrm{~cm}$ ). At the same time, we settled the validation points that were independent of GCP and surveyed the position data using VRS-GPS. Using these GCPs, we conducted an SfM analysis and reconstructed the river morphology.

\subsection{Data analysis}

We conducted a movable riverbed simulation using the Nays 2DH software from iRIC. Nays 2DH was used to simulate movable riverbeds on a GUI and its accuracy and practicability have been evaluated by not only river engineers who belong to the Japan Society of Civil engineering but also those from other Asian regions. In the Chikuma River, two middle floods $(\approx 500 \mathrm{~m} 3 / \mathrm{s})$ and one big flood $(750 \mathrm{~m} 3 / \mathrm{s})$ occurred and disturbed the river morphology and created the gravel bed condition. We simulated the movable riverbed using these three floods as the boundary conditions. 
We settled the two simulation cases. Case 1 used the river morphology data calculated by the UAV and SfM data obtained on 5 July as the initial conditions and simulated the river morphology after the three floods. Case 2 used the river morphology data interpolated by the cross-sectional field survey data based on a 50-m pitch, which were surveyed for planned river excavation works and also simulated the river morphology after the three floods.

Afterwards, we compared the simulation results of the two simulation cases and then considered the efficiency of using UAV and SfM data in a high-accuracy simulation of the movable riverbed. We evaluated the efficiency from two perspectives. The first was the difference estimation of current flood conditions; the second aspect was accuracy of the reconstruction of changes in river morphology via comparisons with the UAV and SfM difference observation data obtained between on 5 July and on 25 October.

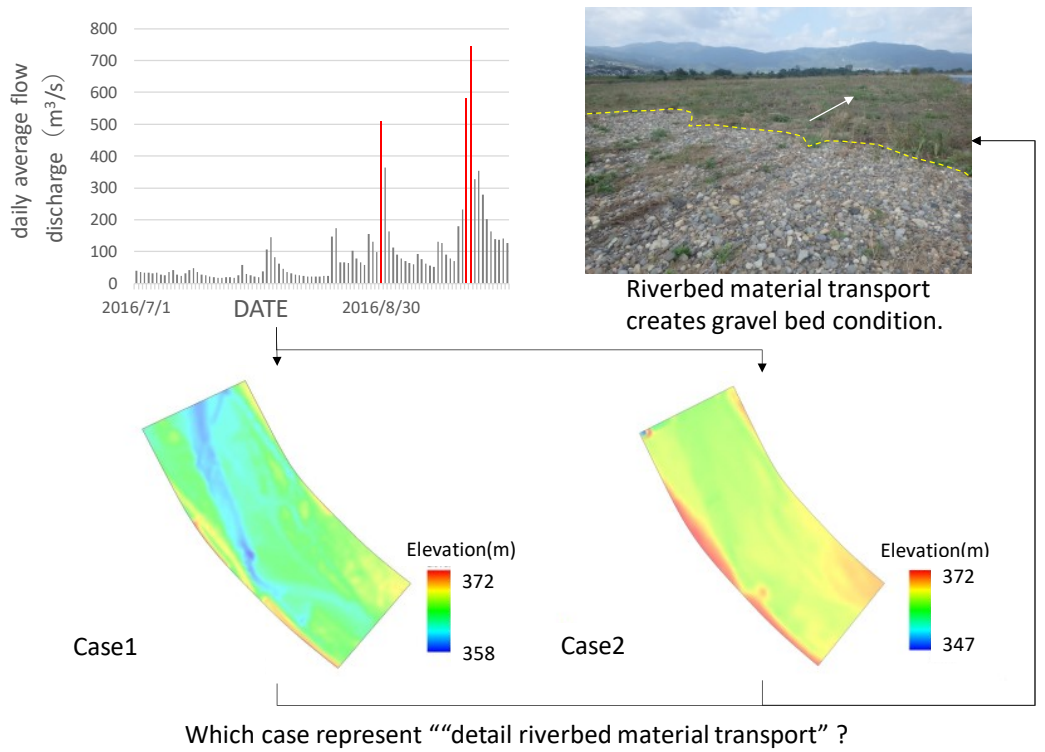

Fig. 5 The schematic of the numerical simulation's comparison

\section{Results}

\subsection{Comparison of flow condition representation}

Fig. 6 indicates the clear differences between Case 1 and Case 2. In Case 1, an exact observation of the river morphology was used to represent the river morphology detail. Lowelevation areas around the main channel and guide channels were represented. These precisions influenced the simulation results related to the condition of the water current, such as depth and velocity. Case 1 results represent the explicit guide channel and contrast of water depth and water current velocity in the guide channel. Case 1 results also reconstructed the contrast of the water current flow between the main channel, guide channels and the river terrace.

Conversely, Case 2 flatly represents the river morphology. This contrast between the two cases influenced the simulation results in Case 2. The simulation results of the water current flow condition in Case 2 cannot explicitly re-connect the guide channels and could not clearly reconstruct the different of depths and velocities in the main channel. The simulation results in Case 2 only represented a flat inundation condition on the river terrace. 

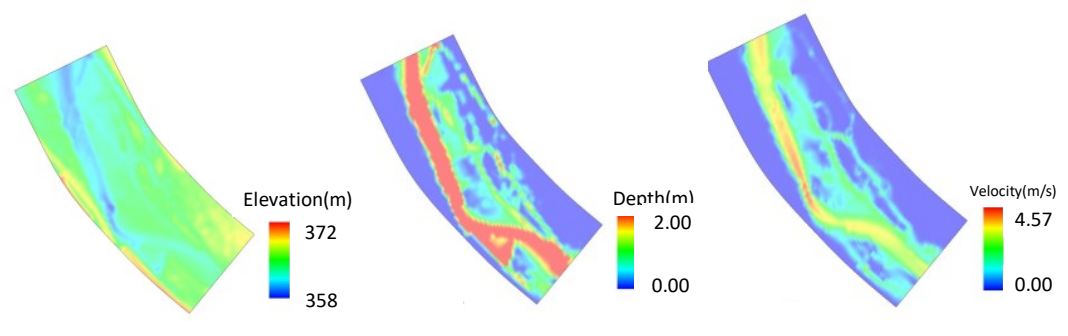

Case1
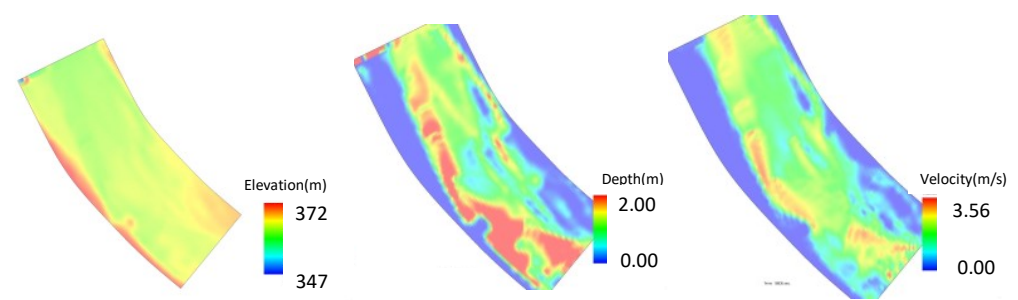

Case2

Fig. 6 Comparison of the flow condition representation

\subsection{Comparison of the differences of elevation change between observed data, Case 1 and Case 2}

Difference in the accuracy of the simulation results clearly influenced the simulation results of the elevation change due to sediment transportation(Fig.7).

Case 1 simulated the detailed elevation change in the guide channels and main channels and the locations of elevation change areas correspond approximately to the locations with observed elevation difference. Conversely, the simulation results in Case 2 only simulate the elevation changes in the main channel. The simulation results in Case 2 could not simulate not only fine sediment transports but also large elevation changes in the guide channel and the river terrace.

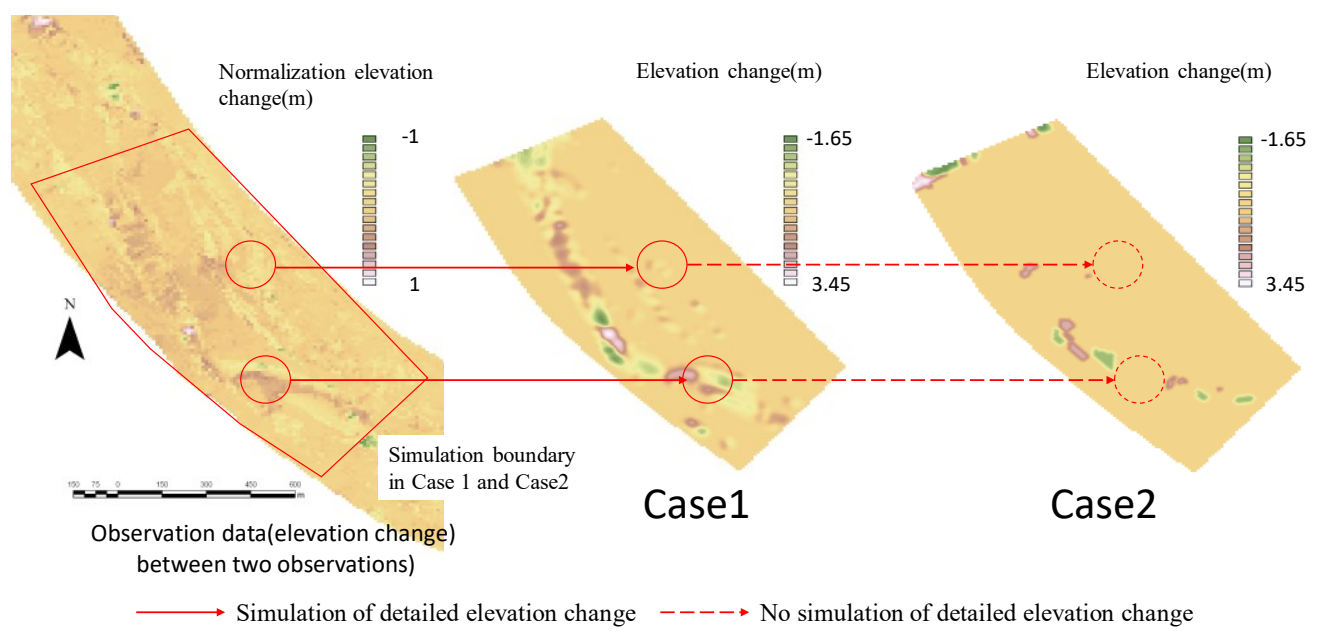

Fig. 7 Comparison of elevation change between observations, Case 1 and Case 2 


\section{Discussion}

\subsection{High-precision effects of movable riverbed simulation}

Figs. 6 and 7 indicate one of the practical ways to improve movable riverbed simulation. High-precision river morphology using UAVs offers the ability to improve the movable riverbed simulation. Sediment transport rate equations, as the first type of improvement mentioned in the Introduction, required many laboratory experiments in the earlier days and requires many trial simulations at present, changing the parameter and boundary condition. However, comparing with the studies and developments of sediment transport rate equations, we can easily simulate and improve the detailed riverbed materials' transports using highprecision river morphology data observed via UAVs. These results indicate the performance and potential of UAVs with regard to the movable riverbed simulation.

\subsection{Possibility of UAVs for the improvement of vegetation dynamics model}

In this research, we initially reported only a movable riverbed simulation. However, the aims of this study are development of vegetation dynamics via data from simulation, which is defined by a fusion of observation techniques and simulation methods. The results from this research indicate that the high-precision effects of the initial condition increase the possibility of a detailed description of the riverbed materials' transport that affect the vegetation dynamics. Along with the schematic in Fig. 4, vegetation dynamics models, which can reconstruct and predict the complex vegetation dynamics, will be developed. And using these models, Japanese river researchers and river engineers can control the conditions of the gravel riverbed and woodland overgrowth and ensure that Japanese rivers environments retain their natural states.

\section{References}

1. X. You, J. Liu, and L. Zhang: Ecological modelling of riparian vegetation under disturbance: A review, Ecological modelling 318, pp.293-300, (2015).

2. R. Benjankar, G. Egger, K. Jorde, P. Goodwin, N. F. Glenn:Dyanmic floodplain vegetation model development for the Kootenai River, USA, Journal of Environmental Management 92, pp.3058-3070, (2011).

3. C.N.Chen, C.H. Tsai and C.T. Huang and W.C.Lo: Application of a two-dimensional hydraulic sediment transport model to estimate dredged location and dredged amount, River Flow 2016, pp.1377-1382, (2017)

4. A.Tamminga, C.Hugenholtz, B.Eaton, M. Lapontee: Hyperspecial remote sensing of channel reach morphology and hydraulic fish habitat using an un manned aerial vehicle(UAV): A first assessment in the context of river research and management, River research and applications 31: pp.379-391, (2015).

5. Hisahi Iwai, Masatoshi Denda, Hiroaki Kubo, Tooru hirabayashi, Shinji Honda, Akihiro Ogawa, Yuichi Kayaba: Proposal of restoration method of gravel bed diver by combining planar excavation and excavation utilization old channel section, river engineering 23, pp.513-518, (2017) (in Japanese). 